\title{
FORMULATION AND IN VITRO EVALUATION OF BROMOCRIPTINE MESYLATE AS FAST DISSOLVING ORAL FILM
}

\author{
MANAR ADNAN TAMER ${ }^{a}$, SHAIMAA NAZAR ABD-AL HAMMID ${ }^{b}$, BALQIS AHMEDc
}

Department of Pharmaceutics, College of Pharmacy, University of Baghdad, Iraq

Email: manaradnan50@yahoo.com

Received: 16 Sep 2017, Revised and Accepted: 28 Nov 2017

\begin{abstract}
Objective: The aim of this study was to formulate and in vitro evaluate fast dissolving oral film of practically insoluble bromocriptine mesylate to enhance its solubility and to improve its oral bioavailability by avoiding first pass effect as well as to produce an immediate release action of the drug from the film for an efficient management of diabetes mellitus type II in addition to an improvement of the patient compliance to this patientfriendly dosage form.

Methods: The films were prepared by the solvent casting method using hydroxypropyl methylcellulose of grades (E3, E5, E15), polyvinyl alcohol (PVA), pectin and gelatin as film-forming polymers in addition to polyethene glycol 400 (PEG400), propylene glycol (PG) and glycerin were used as a plasticizer. Poloxamer 407 was used as a surfactant, sodium saccharin as a sweetening agent, citric acid as a saliva stimulating agent, vanilla as a flavouring agent and crospovidone as a super disintegrant. The prepared films then tested for physical characterization, thickness, weight uniformity, mechanical characteristics (folding endurance, tensile strength, percent elongation and Young's modulus), surface pH, in vitro disintegration time, drug content and an in vitro drug release.
\end{abstract}

Results: Films were found to be satisfactory when evaluated for physical characterization, thickness, weight uniformity, mechanical tests, in vitro disintegration time, folding endurance, drug content and an in vitro drug release. The surface pH of all the films was found to be neutral or minor change. Films in vitro drug release studies were also done using USP dissolution apparatus type II (paddle type). The in vitro drug release profile in the optimized formulation $\mathrm{F} 14$ was gave $86.8 \%$ of drug released at 2 min. The optimized formulation F14 was also showed satisfactory pH $(6.2 \pm 0.2$ ), drug content ( $99.2 \pm 0.5 \%$ ), the disintegration time of $9.2 \pm 0.1$ seconds and the time needed for $80 \%$ of medication to be released (T $80 \%$ ) was 1.35 minute.

Conclusion: The bromocriptine mesylate fast dissolving oral film was formulated. The given film disintegrates within nine seconds which release the drug rapidly and gives an action.

Keywords: Bromocriptine mesylate, Fast dissolving oral film, Solvent casting method

(C) 2018 The Authors. Published by Innovare Academic Sciences Pvt Ltd. This is an open access article under the CC BY license (http://creativecommons.org/licenses/by/4.0/J DOI: http://dx.doi.org/10.22159/ijap.2018v10i1.22615

\section{INTRODUCTION}

Among all routes of drug administration, the oral route is one of the most favored routes, as it is more convenient, cost-effective, and ease of administration lead to high level of patient compliance, but the problem associated with this route is the swallowing difficulty for pediatric and geriatric patients who have a fear of choking. In addition to that, patient convenience and compliance-oriented research have resulted in present safer and newer drug delivery systems [1].

Buccal drug delivery recently becomes an important route of drug administration in which problems like high first-pass metabolism and drug degradation in the gastrointestinal environment can be avoided by administering the drug through buccal route [2].

Drug delivery via the oral mucosa is a promising route when one wishes to achieve a rapid onset of action or an improved bioavailability for drugs which have a high first-pass metabolism. Thus, fast dissolving films allow the films to dissolve in the mouth, so the drug gets directly absorbed into the systemic circulation through the oral mucosa [3].

Oral fast dissolving films (OFDFs) are the most advanced form of an oral solid dosage form. These are solid dosage forms, which disintegrate or dissolve within a minute when placed in the mouth without drinking water or chewing. The oral films are formulated using polymers, plasticizer, flavors, colors, and sweeteners. OFDFs are prepared using hydrophilic polymers that rapidly dissolves in the oral cavity delivering the drug to the systemic circulation. Watersoluble polymers are used in OFDFs as they achieve rapid disintegration. Plasticizer helps to enhance the flexibility of the strip and reduces the brittleness of the strip [4].
The films are intended to place in the buccal cavity, and fewer doses are required which improves the patient compliance. Stability of the dosage form can also be enhanced when formulated as a film. Also, the ODF is a solid unit dosage form provides an accurate dosing and a great precision [5].

Bromocriptine is a semisynthetic ergot alkaloid that interacts with D2 dopamine receptors to inhibit spontaneous and TRH-induced release of prolactin. It is used in neuroleptic malignant syndrome, acromegaly, infertility, hyperprolactinemia, prolactinoma, Parkinson's disease, and type 2 diabetes mellitus. It was approved by the Food and Drug Administration (FDA) in May 2009, for the treatment of type 2 diabetes [6].

Bromocriptine mesylate is rapidly absorbed, after oral administration, the bioavailability of the drug is $28 \%$ of the oral dose consumed, and the plasma protein binding amounts to $96 \%$. It is highly distributed in the liver, stomach, and intestine. The drug is extensively metabolized in the liver. The fate of bromocriptine mesylate primarily involves with renal excretion of two major metabolites accounting for $6 \%$ of the total dose. The elimination of the parent drug from the plasma is biphasic with a terminal half-life of $15 \mathrm{~h}$. Bromocriptine mesylate stimulates dopamine type-II receptors and antagonizes type-I receptors in the hypothalamus and neostriatum of the CNS [7].

Bromocriptine mesylate acts centrally as an antidiabetic agent by a novel mechanism and reduces plasma glucose, triglycerides, free Fatty Acid (FFA) levels, and possibly cardiovascular events [8].

The aim of this study was to formulate and in vitro evaluate a fast dissolving oral film of practically insoluble bromocriptine mesylate to enhance its solubility of drug and to improve its oral 
bioavailability of drugs by avoiding first pass effect as well as to produce an immediate release action of drug from the film for an efficient management of diabetes mellitus type II in addition to an improvement of the patient compliance to this patient-friendly dosage form.

\section{MATERIALS AND METHODS}

\section{Material}

Bromocriptine mesylate was purchased from Avril Chemical Limited, China. HPMC E3, E5, E15, PVA, pectin and gelatin was purchased from Hangzhou Hyper Chemical Limited, China. Poloxamer 407 was purchased from Hangzhou Hyper Chemical Limited, China. PEG400, glycerin was purchased from Fluka Chemical AG, Switzerland. Propylene glycol was purchased from Evans Medical Ltd, Liverpool, England. All other chemicals and solvents were of analytical reagent grade, and deionized water also was used in this study.

\section{Method}

\section{Determination of $\lambda$ max}

$10 \mathrm{mg}$ of bromocriptine mesylate was dissolved in $100 \mathrm{ml}$ of $0.1 \mathrm{~N}$ $\mathrm{HCl}(\mathrm{pH} \mathrm{1.2)}$ and phosphate buffers $(\mathrm{pH} 6.8)$ with $(0.5 \% \mathrm{w} / \mathrm{v}$ Brij$35)$ individually to make a stock solution of concentration $(0.1$ $\mathrm{mg} / \mathrm{ml}$ ). Then From this prepared stock solution, a diluted solution $(0.065 \mathrm{mg} / \mathrm{ml})$ was established and determined the $\lambda \max$ of bromocriptine mesylate using UV spectrophotometric analysis at $200-400 \mathrm{~nm}$.

\section{Construction of calibration curves}

Calibration curves for bromocriptine mesylate in $0.1 \mathrm{~N} \mathrm{HCl}$ and phosphate buffers $(\mathrm{pH} 6.8)$ with $(0.5 \% \mathrm{w} / \mathrm{v}$ Brij-35) were made by preparing consecutive dilutions of the drug from a stock solution $(0.1 \mathrm{mg} / \mathrm{ml})$, samples $(65,55,45,35,25$ and $15 \mu \mathrm{g} / \mathrm{ml})$ were then analyzed by spectrophotometric method for bromocriptine mesylate at its $\lambda$ max $(305 \mathrm{~nm})[7]$.

\section{Determination of saturation solubility of bromocriptine mesylate}

The solubility of Bromocriptine Mesylate was determined by dissolving the excess amount of drug in different medium $0.1 \mathrm{~N} \mathrm{HCl}$, phosphate buffer( $\mathrm{pH}$ 6.8) and phosphate buffer (pH 6.8) containing $0.5 \% \mathrm{w} / \mathrm{v}$ Brij-35) at room temperature and kept for $48 \mathrm{~h}$ with regular shaking. The solutions were centrifuged then filtered and examined by using UV-spectrophotometer at its $\lambda$ max, and from this absorbance, the concentration of that saturated solution was determined which represents the solubility of bromocriptine mesylate in these solutions.

Method for preparation of fast dissolving oral film of bromocriptine mesylate

Fourteen formulas were prepared (F1-F14) as listed in (table 1) by using solvent casting technique; every film of about $4 \mathrm{~cm} 2$ area must contain $0.8 \mathrm{mg}$ of bromocriptine mesylate. The size and number of films that formulated for every group designed as the following:

Each film with an area of $4 \mathrm{~cm} 2(2 \mathrm{~cm} \times 2 \mathrm{~cm})$ and contain $0.8 \mathrm{mg}$ of bromocriptine mesylate.

The amount of drug in the film was calculated as follows:

The dose of the drug to be incorporated in each $4 \mathrm{~cm}^{2}$ film $=0.8 \mathrm{mg}$ of bromocriptine mesylate.

Diameter of petri dish $=11 \mathrm{~cm}$, so that the radius $=5.5 \mathrm{~cm}$.

Area of Petri dish $=\pi \mathrm{r} 2=3.14 \times(5.5 \mathrm{~cm})^{2}=94.985 \mathrm{~cm}^{2}$ approximately $=95 \mathrm{~cm}^{2}$.

Number of $4 \mathrm{~cm} 2$ films obtained from main film $=95 \mathrm{~cm}^{2} \div 4 \mathrm{~cm}^{2}=$ 23.75 films approximately $=24$ films each with area $4 \mathrm{~cm}^{2}$.

Amount of drug in the area considered $=24$ film $\times 0.8 \mathrm{mg}=19.2 \mathrm{mg}$

The fast-dissolving oral films of bromocriptine mesylate were prepared by solvent casting method using: hydroxypropyl methylcellulose (HPMC) with different grades like HPMC E3, E5, and E15, and another type of hydrophilic polymers as the film-forming polymers, PEG 400, propylene glycol (PG) and glycerin were used as plasticizer, poloxamer 407 as a surfactant, citric acid as a saliva stimulating agent, sodium saccharin as a sweetening agent, vanilla as a flavoring agent and crospovidone as a super disintegrant. The considered quantity of film-forming polymer was dissolved in $20 \mathrm{ml}$ of solvent (distilled water) with constant stirring by using magnetic stirrer for two $\mathrm{h}$ to form a homogenous polymeric solution. To this polymeric solution, a suitable amount of plasticizer was added with a continuous stirring for another one $h$. The next step was that, the drug (bromocriptine mesylate), surfactant, saliva stimulating agent and sweetener were dissolved in $10 \mathrm{ml}$ of water and ethanol as a cosolvent ( $5 \mathrm{ml}$ water $+5 \mathrm{ml}$ ethanol) in another beaker to form clear solution, mix the two solutions using magnetic stirrer for one hour, the solution was kept in a sonicator for degassing. Then the bubble free solution was cast on to a petri dish with a diameter of $11 \mathrm{~cm}^{2}$ and kept in hot air oven $\left(60^{\circ} \mathrm{C}\right)$ overnight. The dried film was then removed and cut into the desired shape and size $(2 \mathrm{~cm} \times 2 \mathrm{~cm})$ for the intended application. Cuts or defectiveness were omitted from the study [9].

Table 1: Composition of bromocriptine mesylate oral films formulas

\begin{tabular}{|c|c|c|c|c|c|c|c|c|c|c|c|c|c|c|}
\hline $\begin{array}{l}\text { Ingredients present } \\
\text { in each film (mg) }\end{array}$ & F1 & F2 & F3 & F4 & F5 & F6 & F7 & F8 & F9 & F10 & F11 & F12 & F13 & F14 \\
\hline $\begin{array}{l}\text { Bromocriptine } \\
\text { mesylate }\end{array}$ & 0.8 & 0.8 & 0.8 & 0.8 & 0.8 & 0.8 & 0.8 & 0.8 & 0.8 & 0.8 & 0.8 & 0.8 & 0.8 & 0.8 \\
\hline HPMC E3 & 25 & & & & & & & & & & & & & \\
\hline HPMC E5 & & 25 & & & & & 27.5 & 30 & 25 & 25 & 25 & 25 & 25 & 25 \\
\hline HPMC E15 & & & 25 & & & & & & & & & & & \\
\hline Polyvinyl alcohol & & & & 25 & & & & & & & & & & \\
\hline Pectin & & & & & 25 & & & & & & & & & \\
\hline Gelatin & & & & & & 25 & & & & & & & & \\
\hline $\begin{array}{l}\text { Polyethylene glycol } \\
400\end{array}$ & 10 & 10 & 10 & 10 & 10 & 10 & 10 & 10 & & & 7.5 & 12.5 & 12.5 & 12.5 \\
\hline $\begin{array}{l}\text { Propylene glycol } \\
\text { Glycerin }\end{array}$ & & & & & & & & & 10 & 10 & & & & \\
\hline Poloxamer 407 & 2.5 & 2.5 & 2.5 & 2.5 & 2.5 & 2.5 & 2.5 & 2.5 & 2.5 & 2.5 & 2.5 & 2.5 & 2.5 & 2.5 \\
\hline Crospovidone & & & & & & & & & & & & & 0.5 & 1.5 \\
\hline Citric acid & 2.5 & 2.5 & 2.5 & 2.5 & 2.5 & 2.5 & 2.5 & 2.5 & 2.5 & 2.5 & 2.5 & 2.5 & 2.5 & 2.5 \\
\hline Vanilla & 2.5 & 2.5 & 2.5 & 2.5 & 2.5 & 2.5 & 2.5 & 2.5 & 2.5 & 2.5 & 2.5 & 2.5 & 2.5 & 2.5 \\
\hline Sodium saccharin & 2.5 & 2.5 & 2.5 & 2.5 & 2.5 & 2.5 & 2.5 & 2.5 & 2.5 & 2.5 & 2.5 & 2.5 & 2.5 & 2.5 \\
\hline
\end{tabular}




\section{Evaluation of fast dissolving oral film of bromocriptine mesylate}

\section{Physical characterization of the prepared films}

Physical characterization can be carried out by visual inspection for characteristics such as color, thickness, brittleness, peeling ability, transparency, surface smoothness, tack property and film-forming capacity [10]

\section{Weight variation}

Weight variation test confirms the uniformity of the film formed. Ten randomly selected films from each patch (each of $2 \mathrm{~cm} \times 2 \mathrm{~cm}$ ) were cut and weighed individually and matched with the mean weight for deviation [11].

\section{Thickness measurements}

Film thicknesses were determined using the Digimatic and Vernier Caliper. Each wafer was measured at five positions (central and the four corners) the mean thickness was calculated. This test was performed on six films of each formulation and mean \pm S. D calculated [12].

\section{Drug content uniformity}

This test was done by using the procedure described in United States Pharmacopoeia in which a solvent solution was prepared by dissolving $1 \mathrm{~g}$ of tartaric acid in $500 \mathrm{ml}$ of water, then $500 \mathrm{ml}$ of methanol was added with mixing.

A standard solution was prepared, which consists of bromocriptine mesylate, dissolved in the solvent solution at a concentration of 0.04 $\mathrm{mg} / \mathrm{ml}$.

The test solution was prepared by transferring a tablet, for which the drug content to be determined, into a volumetric flask contains the $15 \mathrm{ml}$ solvent solution. It was shaken mechanically for $30 \mathrm{~min}$ then diluted with the solvent solution up to $25 \mathrm{ml}$ with mixing, after filtration, $10 \mathrm{ml}$ of the clear filtrate was diluted to $50 \mathrm{ml}$.

Then the following equation was utilized to determine the film content of bromocriptine mesylate:

Bromocriptine mesylate content in $\mathrm{mg}=(\mathrm{TC} / \mathrm{D})(\mathrm{At} / \mathrm{As})$

In which $\mathrm{T}$ is the labeled quantity, in $\mathrm{mg}$, of bromocriptine mesylate in the film, C is the concentration, in microgram per $\mathrm{ml}$, of bromocriptine mesylate in the standard solution, D is the concentration in microgram per $\mathrm{ml}$, of bromocriptine in the solution from the film, based upon the labeled quantity in the film and the extent of dilution, while At and As are the absorbance of the solution from the film and the standard solution [13].

\section{Determination of surface $\mathrm{pH}$}

The determination of surface $\mathrm{pH}$ is important to investigate opportunity of any side effects when using the ODFs in vivo, because the acidic or basic $\mathrm{pH}$ may irritate the mucosal membrane of an oral cavity. To measure the $\mathrm{pH}$ value of ODF one strip was allowed to dissolve in $2 \mathrm{ml}$ of distilled water and the $\mathrm{PH}$ of the obtained solution is determined using $\mathrm{pH}$-meter.

Different $\mathrm{pH}$ value will be expected because of the fact of using a different film forming polymers in the formulation of ODFs along with the drug [14].

\section{Folding endurance}

Folding endurance is measured by manual repeated folding of the film at the same place till it broke. The number of time the film is folded without breaking is known as the folding endurance value. A strip of $2 \times 2 \mathrm{~cm}$ diameter (an area of $4 \mathrm{~cm} 2$ ) was subjected to folding endurance by folding the film at the same place repeatedly several times until a visible crack was observed, and the average values were calculated and reported. Folding endurance more than 300 indicating that the formulation good tough and flexible $[15,16]$.

\section{Tensile strength}

It is the maximum value of forces applied to the film at which its breakdowns. The tensile strength was determined by way of holding a film of $5 \mathrm{~cm} \times 2 \mathrm{~cm}$ (which must be pure from air bubbles or any physical defectiveness and cut as dumbbell-shaped) longitudinally in the tensometer, Then the ODFs were drawn at a level of $10 \mathrm{~mm} / \mathrm{min}$. The tensile strength was measured mathematically by dividing the applied force at which the film is broken by the cross-section area of the stripe and was expressed in force per unit area: mega Pascal $(\mathrm{MPa})$ as shown in the following equation [16].

Tensile Strength $=$ Load to Break $/$ Width $\times$ Thickness $\times 100$

\section{Percent of elongation}

When stress is applied the film sample stretches and is referred to as strain. The strain is the deformation of the film divided by the original dimension of the film. Elongation of the film increases as the plasticizer concentration increases. Percentage elongation was calculated by measuring the increase in the length of the film after tensile strength measurement by using the following formula [17]:

Percentage Elongation $=[$ Final length-initial length $]$ X 100/initial length

\section{Young's modulus (YM)}

Young's modulus or elastic modulus is the measure of the stiffness of strip. It is represented as the ratio of applied stress over strain in the region of elastic deformation as follows:

Young's modulus $=$ Slope X 100/Strip thickness X Cross-head speed

Hard and brittle strips demonstrate a high tensile strength and Young's modulus with small elongation [18].

\section{Percent moisture loss (PML)}

The films were weighed accurately and kept in a desiccator containing anhydrous calcium chloride. After three days the films were taken out and weighed. The moisture loss was calculated using the formula [19]:

$$
\% \text { Moisture content }=\frac{\text { Initial weight }- \text { final } \text { weight }}{\text { Initial weight }} \times 100
$$

\section{Percent moisture absorb (PMA)}

This test was carried out to check the physical stability of films at high humid conditions. In the present study, the moisture absorption capacity of the bromocriptine mesylate fast dissolving films were determined by keeping the pre-weighed films in the desiccator containing a saturated solution of potassium chloride, which maintains $79.5 \%$ relative humidity at room temperature for $72 \mathrm{~h}$. Average percentage moisture absorption of three films can be calculated by the following equation [20]:

$$
\% \text { Moisture absorption }=\frac{\text { Final weight }- \text { Initial weight }}{\text { Initial weight }} \times 100
$$

\section{In vitro disintegration time (DT)}

DT is the time at which the fast dissolving oral films start to break down or disintegrate (in second). The in vitro DT is measured by using petri dish method. The test is done by taking three films of each patch in a petri dish, and after adding $2 \mathrm{ml}$ of distilled water for each film, the petri-dish was shaken continuously, then measure the time at which the ODFs start to break down or disintegrate. The determination of DT was done in triplicate for all the formulations [21].

\section{In vitro dissolution study}

The dissolution study was carried out using USP type II (paddle apparatus) with $300 \mathrm{ml}$ of Phosphate buffer $\mathrm{pH} 6.8$ with $(0.5 \% \mathrm{w} / \mathrm{v}$ Brij-35) as a dissolution medium maintained at $37 \pm 0.5{ }^{\circ} \mathrm{C}$. The medium was stirred at $50 \mathrm{rpm}$ for $30 \mathrm{~min}$. Samples were withdrawn by using a syringe at regular intervals $(1,2,3,4,5,10,15$ and $20 \mathrm{~min})$ replaced with fresh medium in order to maintain sink conditions; before analyzing the withdrawn samples using UV-spectrophotometry at $\lambda$ max $305 \mathrm{~nm}$ they must be filtered by using filter syringe $(0.45 \mu \mathrm{m})$.

Samples were suitably diluted with the dissolution media and analyzed for the drug content at $305 \mathrm{~nm}$. Cumulative percent drug release of bromocriptine mesylate was calculated and plotted against time [22]. 


\section{Drug-polymer compatibility study}

\section{Fourier transform infrared spectroscopy (FTIR)}

The compatibility of the drug and the formulation was confirmed by IR spectra of pure drug and formulations that were determined by $\mathrm{KBr}$ disc method.

Drug-polymer interactions were studied by FT-IR spectroscopy. The spectrum was recorded for the drug, blank polymer, the physical mixture of polymer and the drug in a ratio (1:1) and the selected formula. Samples were mixed with potassium bromide and pressed in the form of a disc. The disc was analyzed by FTIR spectroscopy from $4000-400 \mathrm{~cm}^{-1}$ [23].

\section{X-ray powder diffraction (XRPD)}

Powder X-ray diffraction can be used to confirm the crystalline nature of materials. So, this information is used to verify whether the substances are crystalline or amorphous. The diffractograms of bromocriptine mesylate as a pure drug and the selected formula were obtained. The study was confirmed by using Shimadzu XRD6000 powder X-ray diffractometer at continuous scan range of $5^{\circ}$. $80^{\circ}$ of $2 \theta$ The operating voltage was $40(\mathrm{kV})$ and current $30 \mathrm{~mA}$ [24].

\section{Statistical analysis}

The results of the experiments are given as a mean of triplicate samples \pm standard deviation and were analyzed according to the one way analysis of variance (ANOVA) at the level of $(\mathrm{P}<0.05)$ to determine if the changes in the applied factors are statistically significant at level of $(P \leq 0.05)$ and non-significant at level of $(p>0.05)$.

\section{RESULTS AND DISCUSSION}

\section{Determination of $\lambda$ max}

Scanning the diluted solutions of bromocriptine mesylate in $0.1 \mathrm{~N}$ $\mathrm{HCl}$ and in $\mathrm{pH} 6.8$ phosphate buffers with $(0.5 \% \mathrm{w} / \mathrm{v}$ Brij-35) by using UV spectrophotometer at range of $200-400 \mathrm{~nm}$ provided the spectra revealed in (fig. 1-A and 1-B) respectively with the same peak for $\lambda \max$ at $305 \mathrm{~nm}$ as reported in reference [7].

\section{Calibration curves of bromocriptine mesylate}

The constructed calibration curves of bromocriptine mesylate in 0.1 $\mathrm{N} \mathrm{HCl} \mathrm{(pH} \mathrm{1.2)} \mathrm{and} \mathrm{phosphate} \mathrm{buffers} \mathrm{(pH} \mathrm{6.8)} \mathrm{With}(0.5 \% \mathrm{w} / \mathrm{v}$ Brij35 ) are shown in (fig. 2-A and 2-B) respectively. A straight line was obtained by plotting the absorbance versus concentration with a high coefficient of determination. This indicates that the calibration curve obeys Beer's law within the range of concentration used.

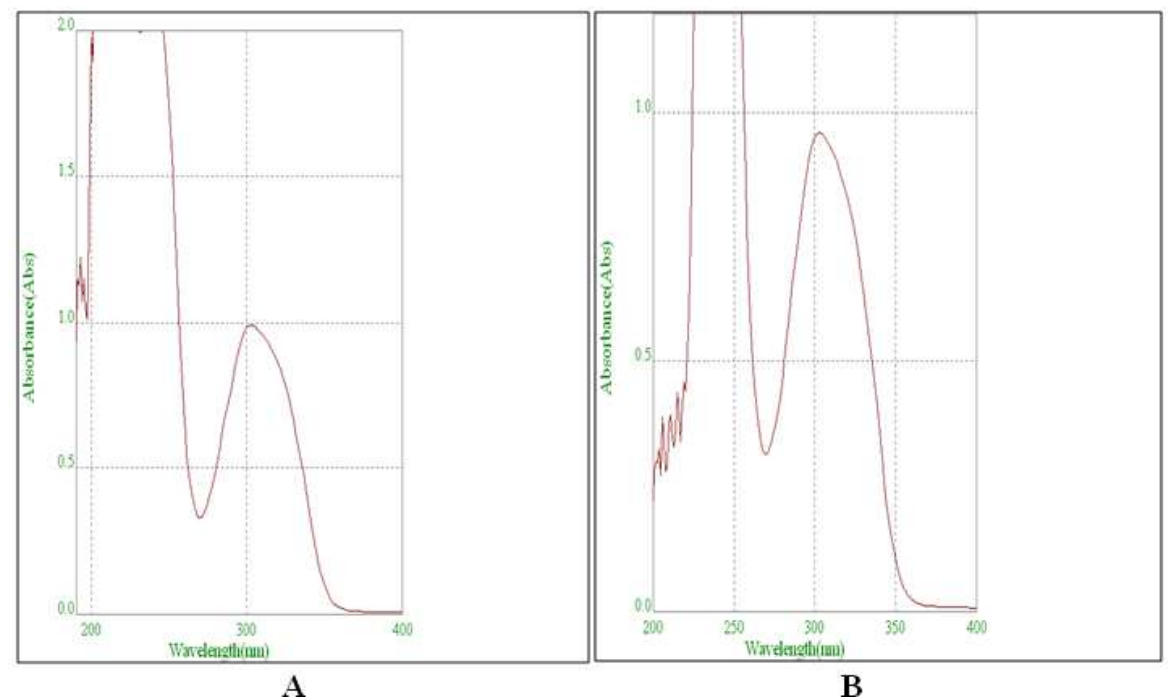

Fig. 1: UV Spectrum of bromocriptine mesylate in A-0.1 N HCl (pH 1.2) B-phosphate buffers (pH 6.8) with (0.5\% w/v Brij-35)

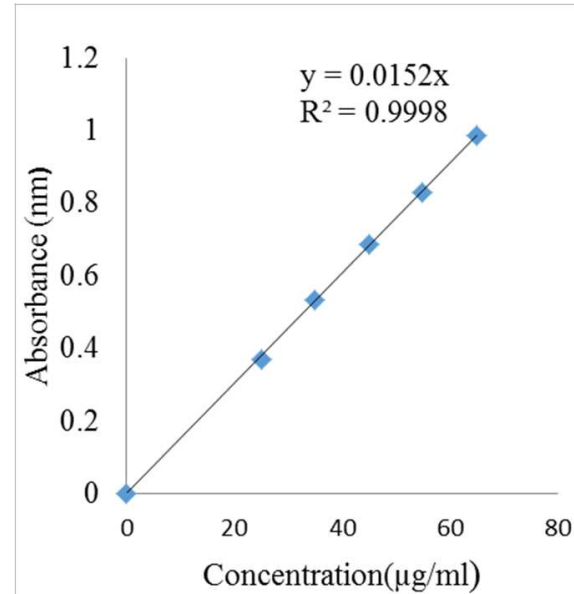

A

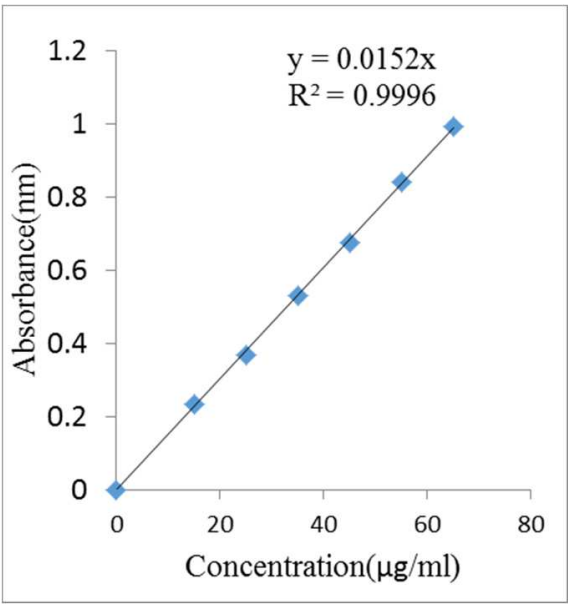

B

Fig. 2: Calibration curve of bromocriptine mesylate in A-0.1 N HCl (pH 1.2) B-phosphate buffers (pH 6.8) with 0.5\% w/v Brij-35. (Results are expressed as mean, $n=3$ ) 


\section{Saturation solubility of bromocriptine mesylate}

The solubility of the drug at acidic $\mathrm{pH}$ was significantly higher than in that of buffer ( $\mathrm{pH} 6.8$ ), as shown in the table (2), this can reflect the alkaline nature of the drug.
Bromocriptine mesylate is practically insoluble in water, so the addition of surfactant (Brij-35) can increase the solubility of bromocriptine mesylate by acting as an excellent solubilizing agent for the drug. It was found that $0.5 \%$ of the Brij-35 act to increase the solubility of bromocriptine mesylate in buffer ( $\mathrm{pH}$ 6.8) up to approximately six-fold.

Table 2: Saturation solubility of bromocriptine mesylate in different media

\begin{tabular}{llll}
\hline Solvent & PH 1.2 & PH 6.8 & PH6.8+0.5\%brij \\
\hline Solubility $(\mu \mathrm{g} / \mathrm{ml})$ mean $\pm \mathrm{SD}^{*}$ & $160 \pm 0.11$ & $24.7 \pm 0.5$ & $158.88 \pm 0.3$ \\
\hline
\end{tabular}

*SD standard deviation from mean, $\mathrm{n}=3$

\section{Visual inspection}

All the prepared fast dissolving films showed homogenous and smooth surface properties which they contain (HPMC of grades E3, E5, E15), PVA, pectin, and Gelatin.

Whereas HPMC and PVA films were transparent, colourless, thin and soft, those prepared from gelatin were thin, soft and semitransparent with yellowish color whereas pectin films turned to be opaque with brown color.

\section{Weight variation}

The outcomes reveal that: the average weights for all the prepared formulations were uniform and fit to the referred values as shown in the table (3), demonstrating that the strategy utilized for the preparation of films is reproducible and give films of uniform weight. The weight of the patches was determined using digital balance. All patches show consistency.

\section{Thickness}

The average thickness values of films for all formulas were shown in the table (3). The thickness was found to vary between $0.08 \pm 0.01$ to $0.12 \pm 0.02 \mathrm{~mm}$. A very low standard deviation value is indicating that the method used for the formulation of films is reproducible and give films of uniform thickness and hence dosage accuracy in each film can be ensured.

\section{Drug content}

The formulated bromocriptine mesylate films showed an acceptable quantity of medicament ranged from $96.9 \pm 1.2 \%-101.6 \pm 0.6 \%$ as shown in the table (3). The accepted range of content uniformity labeled in BP is ranged from $85 \%$ to $115 \%$, so the result of content uniformity is obeying this range this indicating that the solvent casting method used in preparing bromocriptine mesylate fast dissolving oral films is very efficient. On this basis, it was found that the drug was spread uniformly throughout the four $\mathrm{cm}^{2}$ constant area of the films.

\section{Surface pH measurement}

All the prepared films showed an acceptable surface $\mathrm{pH}$ value (5.8 $\pm 0.08-6.3 \pm 0.26)$ as viewed in the table (3) when compared to that $\mathrm{pH}$ of oral mucosa indicating that it does not irritate the oral mucosa.

\section{Percent moisture loss (PML)}

The moisture loss study gives an idea about nature, stability, and ability of films to retain its physicochemical properties under normal storage conditions. It also indicates hydrophilicity of films. All the obtained values are reported in the table (3). The obtained values were almost uniform and ranged from $0.7 \pm 0.5 \%$ to $2.03 \pm 0.4$ $\%$ indicating little moisture loss and stable formulations.

\section{Percent moisture absorb (PMA)}

Moisture uptake study is an essential factor to be determined, as the presence of moisture bearings a critical investigation on drug stability. All the reported values of moisture uptake are listed in the table (3). It was detected that all the polymers were hydrophilic and the moisture absorbed values ranged from $1.35 \pm 0.6 \%$ to $5.5 \pm 0.2 \%$. Moisture uptake had an inverse relation to disintegration time, in another word as the moisture uptake increase the disintegration time decrease.

Table 3: Physical evaluation parameters of bromocriptine mesylate fast dissolving films formulas

\begin{tabular}{|c|c|c|c|c|c|c|c|}
\hline Formula code & $\begin{array}{l}\text { Weight variation } \\
(\mathrm{mg})^{* * *} \text { mean } \pm \text { SD }\end{array}$ & $\begin{array}{l}\text { Thickness } \mathrm{mm})^{* *} \\
\text { mean } \pm S D\end{array}$ & $\begin{array}{l}\text { Drug content* } \\
\text { mean } \pm S D\end{array}$ & $\begin{array}{l}\text { Surface pH* } \\
\text { mean } \pm S D\end{array}$ & $\begin{array}{l}\text { In vitro } \\
\text { DT(s)* } \\
\text { mean } \pm \text { SD }\end{array}$ & $\begin{array}{l}\text { PML }^{*} \\
\text { mean } \pm \text { SD }\end{array}$ & $\begin{array}{l}\text { PMA* } \\
\text { mean } \pm \text { SD }\end{array}$ \\
\hline F1 & $47.3 \pm 0.2$ & $0.08 \pm 0.05$ & $96.9 \pm 0.2$ & $5.9 \pm 0.3$ & $13.2 \pm 0.6$ & $1.5 \pm 0.6$ & $4.7 \pm 0.3$ \\
\hline $\mathrm{F} 2$ & $49.5 \pm 0.1$ & $0.09 \pm 0.02$ & $98.2 \pm 0.8$ & $6.0 \pm 0.2$ & $18.6 \pm 0.1$ & $1.7 \pm 0.55$ & $4.2 \pm 0.55$ \\
\hline F3 & $50.5 \pm 0.4$ & $0.11 \pm 0.01$ & $98.7 \pm 0.5$ & $6.1 \pm 0.6$ & $29 \pm 0.5$ & $1.4 \pm 0.26$ & $3.2 \pm 0.28$ \\
\hline F4 & $49.6 \pm 0.2$ & $0.1 \pm 0.05$ & $100.3 \pm 0.5$ & $5.9 \pm 0.15$ & $61 \pm 0.3$ & $2.03 \pm 0.4$ & $3.35 \pm 0.6$ \\
\hline F5 & $48.9 \pm 0.5$ & $0.09 \pm 0.03$ & $97.82 \pm 0.3$ & $5.8 \pm 0.08$ & $49.3 \pm 0.2$ & $1.67 \pm 0.3$ & $1.83 \pm 0.2$ \\
\hline F6 & $49.2 \pm 0.1$ & $0.11 \pm 0.04$ & $99.26 \pm 1.1$ & $5.9 \pm 0.26$ & $20.3 \pm 0.2$ & $1.4 \pm 0.56$ & $4.8 \pm 0.66$ \\
\hline F7 & $50.2 \pm 0.3$ & $0.11 \pm 0.01$ & $101.6 \pm 0.6$ & $6.1 \pm 0.7$ & $28.5 \pm 0.5$ & $1.6 \pm 0.5$ & $3.26 \pm 0.3$ \\
\hline F8 & $51.5 \pm 0.2$ & $0.12 \pm 0.02$ & $100.2 \pm 0.4$ & $6.2 \pm 0.5$ & $37.6 \pm 0.1$ & $1.2 \pm 0.17$ & $2.25 \pm 0.2$ \\
\hline F9 & $47.4 \pm 0.2$ & $0.08 \pm 0.01$ & $99.5 \pm 0.55$ & $5.8 \pm 0.2$ & $20 \pm 0.2$ & $1.7 \pm 0.37$ & $2.6 \pm 0.6$ \\
\hline F10 & $48.9 \pm 0.1$ & $0.08 \pm 0.02$ & $98.8 \pm 0.62$ & $6.0 \pm 0.45$ & $19.5 \pm 0.6$ & $1.2 \pm 0.25$ & $2.9 \pm 0.45$ \\
\hline F11 & $49.7 \pm 0.05$ & $0.09 \pm 0.05$ & $98.66 \pm 0.5$ & $6.3 \pm 0.26$ & $24.2 \pm 0.1$ & $1.8 \pm 0.16$ & $3.5 \pm 0.32$ \\
\hline F12 & $50.8 \pm 0.1$ & $0.1 \pm 0.03$ & $99.98 \pm 1.2$ & $6.2 \pm 0.5$ & $14.5 \pm 0.6$ & $0.7 \pm 0.5$ & $5.4 \pm 0.25$ \\
\hline F13 & $49.5 \pm 0.09$ & $0.1 \pm 0.02$ & $99.2 \pm 0.5$ & $6.2 \pm 0.5$ & $11.5 \pm 0.2$ & $1.6 \pm 0.3$ & $5.3 \pm 0.32$ \\
\hline F14 & $49.5 \pm 0.1$ & $0.09 \pm 0.02$ & $99.2 \pm 0.5$ & $6.2 \pm 0.2$ & $9.2 \pm 0.8$ & $1.25 \pm 0.1$ & $5.5 \pm 0.32$ \\
\hline
\end{tabular}

${ }^{*} \mathrm{n}=3,{ }^{* *} \mathrm{n}=6,{ }^{* * *} \mathrm{n}=10$, SD-standard deviation, DT-Disintegration time, PML-Percent moisture loss, PMA-Percent moisture absorb.

\section{Effect of different types of polymers}

Formulas (F1-F6) table (1) were utilized to study the effect of polymer type (HPMC E3, E5, E15, PVA, pectin, and gelatin) on the physical and mechanical properties of the prepared bromocriptine mesylate fast dissolving oral films and also their effect on the drug release profile.

The mechanical properties of ODFs are essential since it related to their stability during storage, shipping, and packaging. 
Tensile strength has been utilized as a marker of the general mechanical prevalence of the film. A high \% elongation value shows that the film is tough and flexible. Folding endurance test results indicated that the films would maintain the integrity with buccal mucosa when applied and has good plasticity. This makes the system acceptable for movement of the mouth, indicating good strength and elasticity. The selected FDOFs must have reasonable tensile strength, a high percentage of elongation, low Young's modulus, short in vitro disintegration time and a high percent of drug release.

The results in the table (3) showed that the lowest disintegration time of the film-forming polymer was HPMC E3 which represent (F1) with disintegration time of $13.2 \mathrm{sec}$.

Different film forming-polymers gave different disintegration time value as shown in the fig. (3):

Table 4: Mechanical properties of bromocriptine mesylate fast dissolving films formulas

\begin{tabular}{llll}
\hline Formula code & $\begin{array}{l}\text { Folding endurance } \\
\text { mean } \pm \text { SD }\end{array}$ & Tensile strength mean \pm SD & $\begin{array}{l}\text { Percent of elongation } \\
\text { mean } \pm \text { SD }\end{array}$ \\
\hline F1 & $36 \pm 0.5$ & $14.368 \pm 0.2$ & $5.87 \pm 0.5$ \\
F2 & $322 \pm 2.5$ & $6.44 \pm 0.16$ & $20.86 \pm 0.8$ \\
F3 & $335 \pm 3.5$ & $8.25 \pm 0.1$ & $21.7 \pm 0.3$ \\
F4 & $652 \pm 5.5$ & $2.78 \pm 0.24$ & $29.33 \pm 0.18$ \\
F5 & $20 \pm 1.0$ & $13.61 \pm 0.5$ & $4.275 \pm 0.2$ \\
F6 & $297 \pm 1.5$ & $7.5 \pm 0.55$ & $11.5 \pm 0.25$ \\
F7 & $345 \pm 2.5$ & $15.2 \pm 0.27$ & $27.13 \pm 0.5$ \\
F8 & $362 \pm 3.5$ & $18.2 \pm 0.15$ & $29.14 \pm 0.66$ \\
F9 & $270 \pm 2.5$ & $7.8 \pm 0.3$ & $18.62 \pm 0.25$ \\
F10 & $254 \pm 1.5$ & $5.1 \pm 0.8$ & $17.35 \pm 0.45$ \\
F11 & $258 \pm 3.65$ & $4.39 \pm 0.5$ & $14.4 \pm 0.5$ \\
F12 & $355 \pm 2.55$ & $4.8 \pm 0.8$ & $25.5 \pm 0.3$ \\
F13 & $358 \pm 2.2$ & $4.9 \pm 0.4$ & $19.6 \pm 0.6$ \\
F14 & $362 \pm 1.2$ & & $18.6 \pm 0.5$ \\
\hline
\end{tabular}

SD-Standard Deviation; $\mathrm{n}=3$.

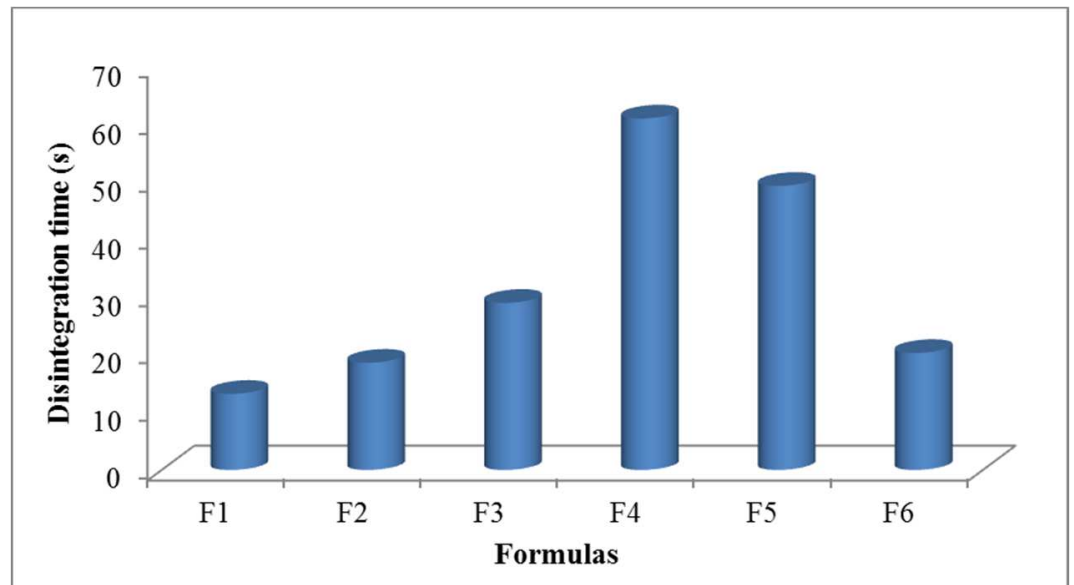

Fig. 3: In vitro disintegration time of different film-forming polymers, (All the values were calculated as mean \pm standard deviation; $n=3$ )

The formula (F1) gave satisfactory $\%$ elongation $(5.87 \pm 0.5 \%)$, but it gives low folding endurance values $(36 \pm 0.5)$, these results were recorded by Bhikshapathi DVRN et al. [10]. Also, HPMC E3 film (F1) was difficult to handling that is recorded by Kumar SK et al. [25].

In the other hand, the films of gelatin (F6) also give low disintegration time $(20.3 \pm 0.2)$ and with good mechanical properties (folding endurance 297) and satisfactory \% elongation $(11.5 \pm 0.25 \%)$. The problem seen by using this polymer was the hard peeling of the film from the petri dish (its peeled as apices) this result also reported by T. Hassanien et al. [26]

While films of PVA (F4) have good mechanical properties with good peeling off and good appearance but with long disintegration time $(61 \pm 0.3 \mathrm{sec}$.) due to the swelling property of this polymer which makes a gel-like layer on the surface of the film upon contact with aqueous media lead to prevent penetration of water to the film, this swelling property increased with increasing of the polymer concentration [27].

The films that prepared with pectin as film-forming polymer gave as shown in the table (3) a relatively long disintegration time $(49.3 \pm 0.2$ sec.) with low folding endurance value $(20 \pm 1)$ and bad mechanical properties (high (percentage of elongation, young's modulus and low percentage of elongation) as shown in table (3) this indicates that the films were brittle and weak. The reason for the brittle film formation was the insufficient concentration of polymer in the formulation [28].

While (F2) (HPMC E5) gave satisfactory \% elongation $(20.86 \pm 0.8)$ and good folding endurance values $(337 \pm 2.5)$, these outcomes were in concurrence with those that reported by Chauhan SS et al. [29].

On the other hand, the film made from HPMC E15 has acceptable mechanical properties, young's modulus $(112.8 \pm 1.2)$ and folding endurance $(335 \pm 3.5)$, but the formulated HPMC E5 film has faster disintegration time than HPMC E15 formula (18.6 \pm 0.1 and 29 \pm 0.5$)$ respectively.

The in vitro dissolution profile of bromocriptine mesylate fast dissolving oral films of the formulas (F2 and F3) as shown in fig. (4).

The values of T80\% for the films prepared with HPMC E5 and HPMC E15 (F2 and F3) was 2.6 and 4.99 min respectively. The difference in the dissolution parameters caused by the variances in viscosity grade of HPMC film-forming polymer. These results agree with the 
result obtained by Pradhan $\mathrm{R}$ et al. by using different grades of HPMC and studying its effect on the release profile of indomethacin and report that drug release decreased with increase in the viscosity of polymer used [30]. From results, the disintegration time in mouth increased with increasing the viscosity of HPMC polymer and with increasing the polymer level in the formulation.

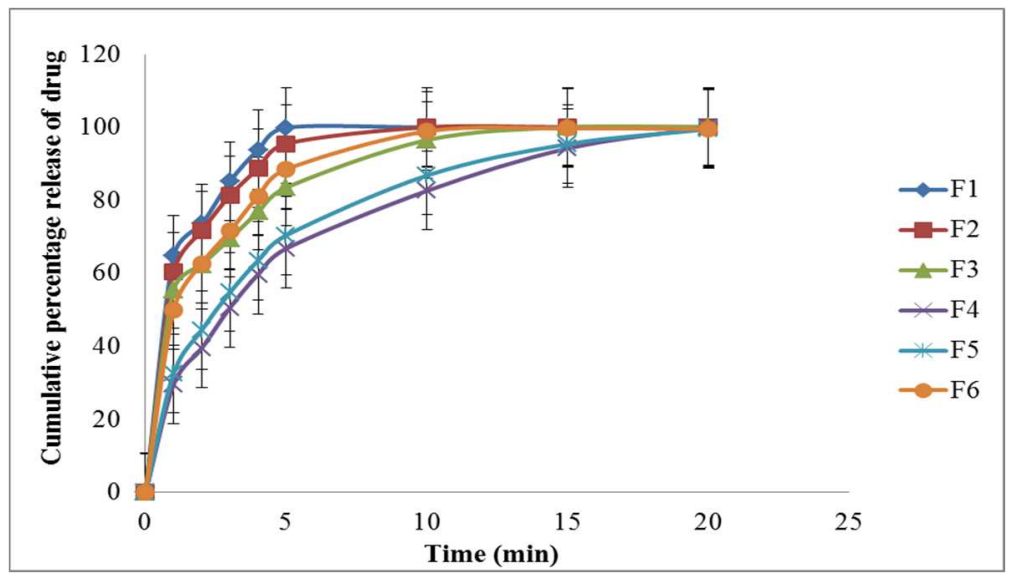

Fig. 4: Effect of polymer type on the dissolution profile of bromocriptine mesylate in phosphate buffer (pH 6.8 ) at $37^{\circ} \mathrm{C}$, (All the values were calculated as mean \pm standard deviation; $n=3$ )

The time needed for $80 \%$ of medication to be released (T80\%) and percent medication dissolved in $2 \mathrm{~min}(\% \mathrm{D} 2 \mathrm{~min}$ ) from the formulated films (F2 and F3) are listed in the table (5). From all these results we found that the HPMC E5 had the best physical, mechanical properties and drug release profile than the other film forming polymers.

Table 5: In vitro dissolution considerations of (F2 and F3)

\begin{tabular}{lll}
\hline Formula & T80\% (min) mean \pm SD & \%D2 min mean \pm SD \\
\hline F2 & $2.6 \pm 0.5$ & $71.6 \pm 0.2$ \\
F3 & $4.99 \pm 0.15$ & $61.4 \pm 0.25$ \\
\hline
\end{tabular}

SD-Standard deviation; $\mathrm{n}=3$; T80\%-time required for $80 \%$ of drug to be released; \%D2 min-cumulative percentage release of drug at 2 min.

\section{Effect of concentrations of selected polymer (HPMC E5)}

According to the physical and mechanical properties and the drug release profile, HPMC E5 was selected as an optimized suitable polymer for prepare fast dissolving bromocriptine mesylate oral film.

So formulas (F2, F7, and F8) of different polymer concentrations $(50 \%, 55 \%$ and $60 \% \mathrm{w} / \mathrm{w})$ respectively were further evaluated to get an optimum suitable polymer concentration by study their dissolution profile parameters.
Table (3) revealed that there is a significantly $(\mathrm{p} \leq 0.05)$ decrease in the invitro DT of the formulated strips with the decrease in concentration of HPMC E5 from $(60 \% \mathrm{w} / \mathrm{w})$ in formula (F8) to $(50 \%$ $\mathrm{w} / \mathrm{w}$ ) in formula (F2).

It appears that films containing a high concentration of polymer resulted in a thicker gel upon contact with the medium, resulting in longer disintegration time as shown in fig. (3). the same result was obtained with metoprolol tartrate strips and lamotrigine fast dissolving films [31, 32].

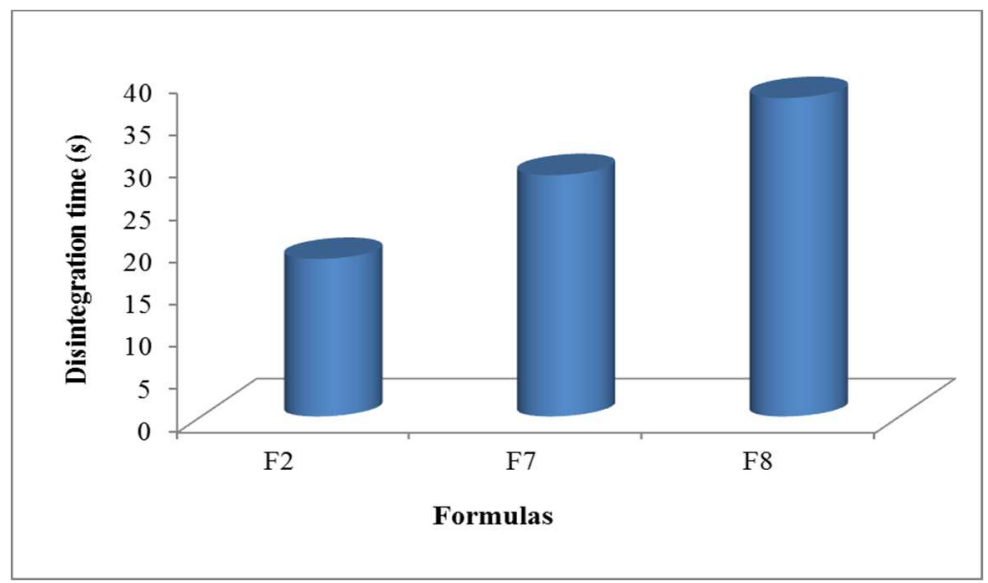

Fig. 5: In vitro disintegration time of different concentration of the selected film-forming polymer (HPMC E5), (All the values were calculated as mean \pm standard deviation; $n=3$ ) 
The results of tensile testing listed in the table (4) that indicate high tensile strength film result from increasing the polymer concentration, this is due to the fact that densely packed chains of HPMC produced from increasing polymer concentration, make the film need more force to breaks [33]. Same findings were found with valsartan film [34].

Also, the results revealed that the percentage elongation and folding endurance of the films were increased with an increase in the concentration of polymer as in table (4), due to increase in the elasticity nature of the polymer [28]. Similar observations were found by Trivedi J et al. [35].

Table (6) shows that the formula (F2) has the highest D2 min (\%) and the lowest $\mathrm{T} 80 \%$ (min) (2.6 min) indicate that F2 which contain the lowest percent of polymer (50\% HPMC E5) gave fastest dissolution rate compared with the other formulas (F7and F8) as shown in fig. (6).
From the dissolution parameters that showed in table (6) for the formulas prepared with a different concentration of the selected polymer HPMC E5 (F2, F7 and F8) which contain $(50 \%, 55 \%$ and $60 \% \mathrm{w} / \mathrm{w}$ respectively), it was seeing that the dissolution rate of bromocriptine mesylate reduces significantly $(p<0.05)$ as the concentration of HPMC E5was increase from $50 \%(\mathrm{w} / \mathrm{w})$ in formula (F2) to $60 \%(\mathrm{w} / \mathrm{w})$ in formula (F8) as shown in fig. (6), this results may be due to that higher concentration of polymer, results in the production of high consistency gel layer created by the close interaction between the particles of HPMC E5 results in a diminished movement of medication particles in swollen lattices, which prompts a decline in dissolution rate [33].

Therefore, HPMC E5 $(50 \% \mathrm{w} / \mathrm{w})$ was considered as the best polymer concentration and was chosen for the design of the subsequent formulas through the study.

Table 6: In vitro dissolution parameters from the prepared oral films (F2, F7, and F8)

\begin{tabular}{lll}
\hline Formula code & T80\%(min) mean \pm SD & D2 min(\%) mean \pm SD \\
\hline F2 & $2.6 \pm 0.5$ & $71.6 \pm 0.2$ \\
F7 & $4.7 \pm 0.25$ & $60.5 \pm 0.55$ \\
F8 & $5.29 \pm 0.3$ & $53.7 \pm 1.25$ \\
\hline
\end{tabular}

SD-Standard deviation; $\mathrm{n}=3$; T80\%-time required for $80 \%$ of drug to be released; $\% \mathrm{D} 2$ min-cumulative percentage release of drug at 2 min.

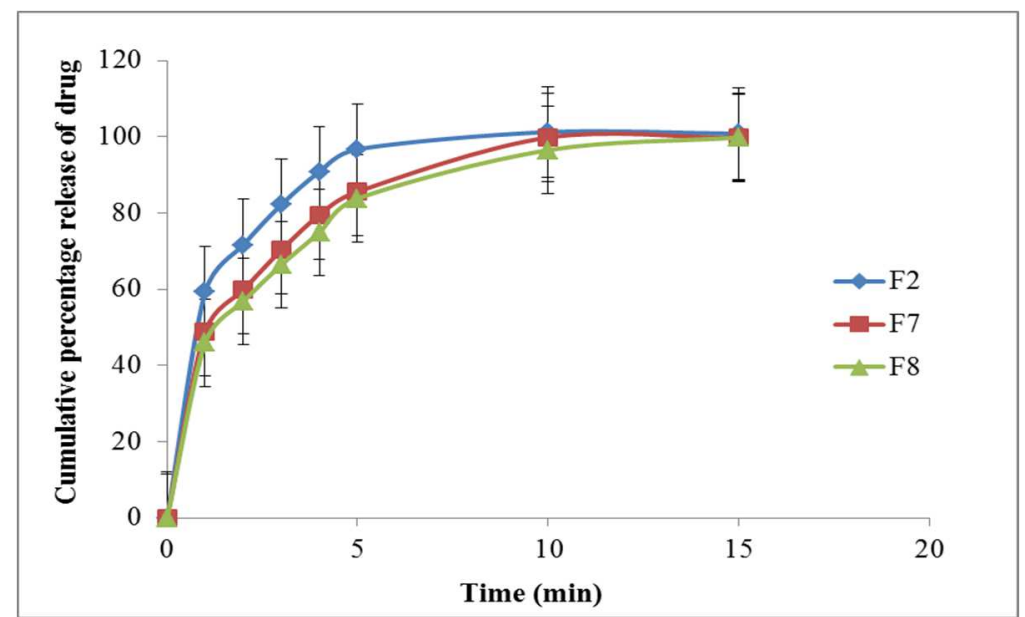

Fig. 6: Cumulative percent of bromocriptine mesylate release of different concentration of HPMC E5 in phosphates buffer (pH 6.8) at $37{ }^{\circ} \mathrm{C}$, (All the values were calculated as mean \pm standard deviation; $n=3$ )

\section{Effect of the type and concentration of plasticizers}

Formulas (F2, F9 and F10) were employed to study the effect of different plasticizer types in concentration $20 \% \mathrm{w} / \mathrm{w}$ (glycerin, PEG 400 and PG) and different concentration of PEG $400(20,20$ and 25 $\% \mathrm{w} / \mathrm{w}$ ) in formulas (F2, F11 and F12) on the mechanical, physical properties and on the dissolution profile of the bromocriptine mesylate FDOFs.

The results showed that changing of plasticizer type caused no significant effect $(p>0.05)$ on the in vitro DT of mouth dissolving strips, as show in fig. (7), this may be due to the fact that three types of plasticizer enhanced the disintegration time by facilitating the penetration of fluids into the strip, since plasticizer alter the densely packed chains of HPMC texture by forming a polymer structure possess more pores and less densely that breaks at lower force, resulting in faster disintegration of the film [36].

The folding endurance of formulation with PEG 400 as a plasticizer were higher compared to other plasticizers. The same result was obtained with diazepam oral strips [37]. On the other hand, HPMC films that plasticized with propylene glycol were patchy and sticky in appearance, while glycerin made soft and tough strips. At the same time, films plasticized with PEG 400 exhibited good physical and mechanical properties such as tensile strength and percentage of elongation as shown in the table (4). These observations are in accordance with Choudhary et al. [38] and Ali MS et al. [37]. So PEG400 was selected for further study of suitability in films formulation.

The time needed for $80 \%$ of medication to be released (T80\%) and percent medication dissolved in $2 \mathrm{~min}$ (D2 $\mathrm{min}$ ) from the formulated films (F2, F9, and F10) are listed in the table (7).

The release profile of bromocriptine mesylate from formulas (F2, F9 and F10) which contain $20 \% \mathrm{w} / \mathrm{w}$ of (PEG 400, PG and glycerin) respectively is displayed in fig. (8). It was seen that changing the plasticizer types had no-significant change $(p>0.05)$ on the dissolution profile of bromocriptine mesylate, this may be because of that the three plasticizers are water dissolvable and they will diffuse out from the films in watery media making void spots in the film through which distribution of liquid happens to enable film breaking down leading to improve release profile of drug [39]. 


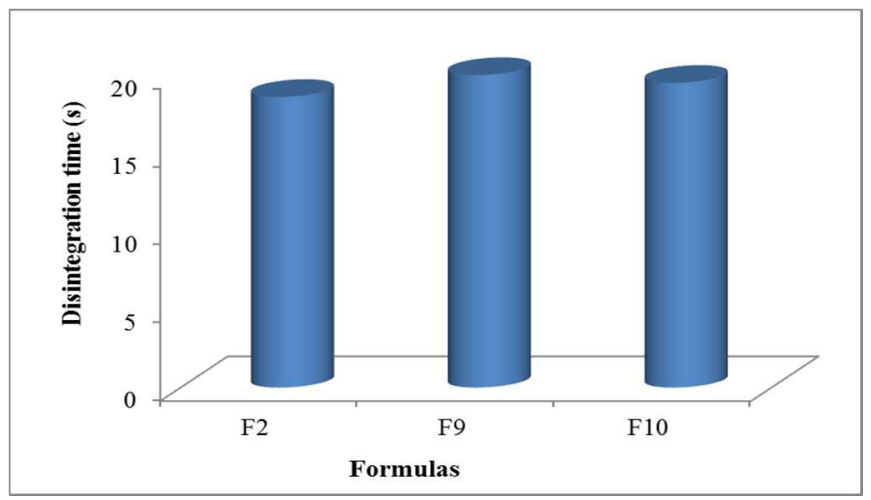

Fig. 7: In vitro disintegration time in seconds of formulas prepared with different types of plasticizer, (All the values were calculated as mean \pm standard deviation; $n=3$ )

Table 7: In vitro dissolution parameters from the prepared oral films (F2, F9, and F10)

\begin{tabular}{lll}
\hline Formula code & T80\% (min) mean \pm SD & D2 min (\%) mean \pm SD \\
\hline F2 & $2.6 \pm 0.5$ & $71.6 \pm 0.2$ \\
F9 & $2.9 \pm 0.2$ & $69.4 \pm 0.55$ \\
F10 & $3.0 \pm 0.15$ & $68.8 \pm 0.8$ \\
\hline
\end{tabular}

SD-Standard deviation; $\mathrm{n}=3$; T80\%-time required for $80 \%$ of drug to be released; \% D2 min-cumulative percentage release of drug at 2 min.

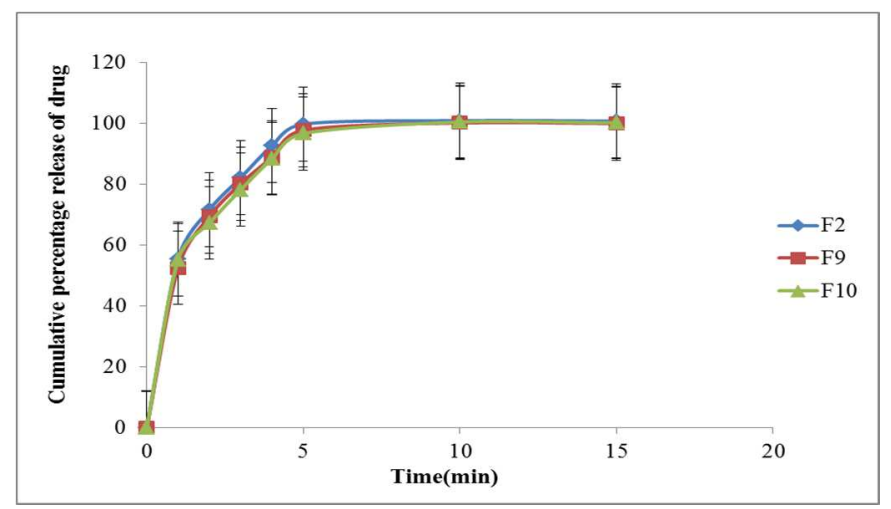

Fig. 8: Cumulative percent of bromocriptine mesylate release from formulas prepared with the different type of plasticizers in phosphates buffer ( $\mathrm{pH} 6.8$ ) at $37^{\circ} \mathrm{C}$, (All the values were calculated as mean \pm standard deviation; $\mathrm{n}=3$ )

Formulas F2, F11, and F12 were used to study the effect of different concentrations of selected plasticizer PEG400 $(20,15$ and $25 \% \mathrm{w} / \mathrm{w}$ of the total film weight) on the in vitro disintegration time, mechanical properties and the drug release profile of the oral film.

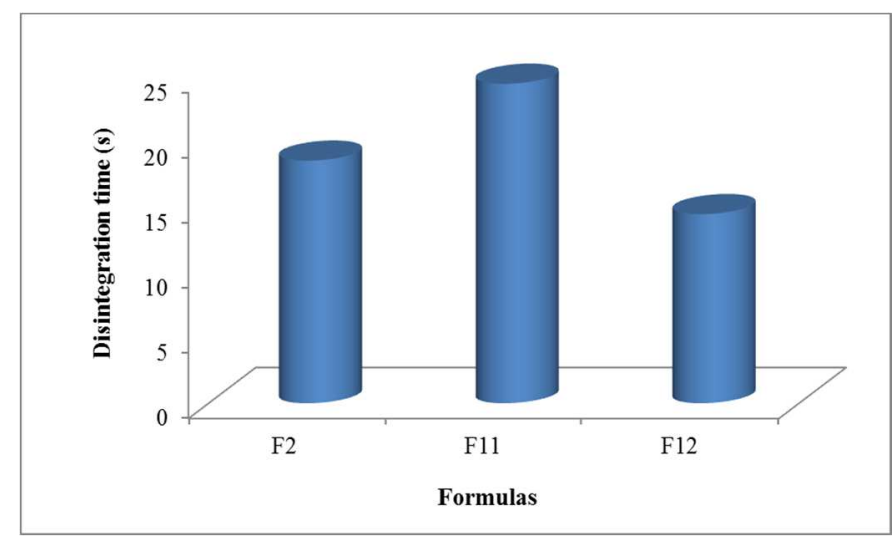

Fig. 9: In vitro disintegration time in seconds of formulas prepared with the different concentration of the selected plasticizer (PEG 400), (All the values were calculated as mean \pm standard deviation; $n=3$ )

Different concentration of PEG400 (20, 15 and 25 \%) which present in formulas (F2,F11 and F12) show a decrease in disintegration time as the plasticizer concentration increased as shown in fig. (9) this occurs because PEG 400 act as a co-solvents that reduce the ability 
of water to squeeze out non-polar, hydrophobic compounds, thus increasing solubility [40].

The mechanical properties of formulas (F2, F11, and F12) are shown in the table (4), which shows that the increase in the plasticizer concentration produced a decrease of the Young's modulus (YM), and the tensile strength (TS). The decrease in tensile strength as a function of plasticizer concentration increase may be due to the weakening of the intermolecular forces between polymer chains, thus leading to decrease the rigidity of three-dimensional structure formed upon drying the film, this leads to a less force to break the film. Moreover, it was seen that the increasing the concentration of plasticizer leading to increasing the percentage of elongation (\%E). These results can be explained by the fact that the plasticizers act as an interior emollient and enhance movement of the polymer chains (lubricity theory) [41].
From the release profile of bromocriptine mesylate from formulas (F2, F11, and F12) which contain 20, 15 and 25\% of PEG 400 respectively that shown in (fig. 10), it was observed that the drug release rate increased significantly $(\mathrm{p}<0.05)$ as the concentration PEG 400 was increased; Here the role of PEG 400 may be a dissolution facilitating agent, therefore increasing concentration will increases the drug release rate [42].

The time needed for $80 \%$ of medication to be released (T80\%) and percent medication dissolved in $2 \mathrm{~min}$ (D2 $\mathrm{min}$ ) from the formulated films (F2, F11and F12) are listed in the table (8).

The dissolution parameters showed that F12 prepared with 25\% PEG400 had the best drug release profile among other formulas prepared with less concentration of PEG400, so F14 was chosen for the design of the subsequent formulas through the study.

Table 8: In vitro dissolution parameters from the prepared oral films (F2, F11, and F12)

\begin{tabular}{lll}
\hline Formula code & T80\%(min) mean \pm SD & D2 min(\%) mean \pm SD \\
\hline F2 & $2.6 \pm 0.5$ & $71.6 \pm 0.2$ \\
F11 & $3.14 \pm 0.3$ & $65.4 \pm 0.8$ \\
F12 & $2.06 \pm 0.25$ & $77.4 \pm 0.65$ \\
\hline
\end{tabular}

SD-Standard deviation; $\mathrm{n}=3$; T80\%-time required for $80 \%$ of drug to be released; \% D2 min-cumulative percentage release of drug at 2 min.

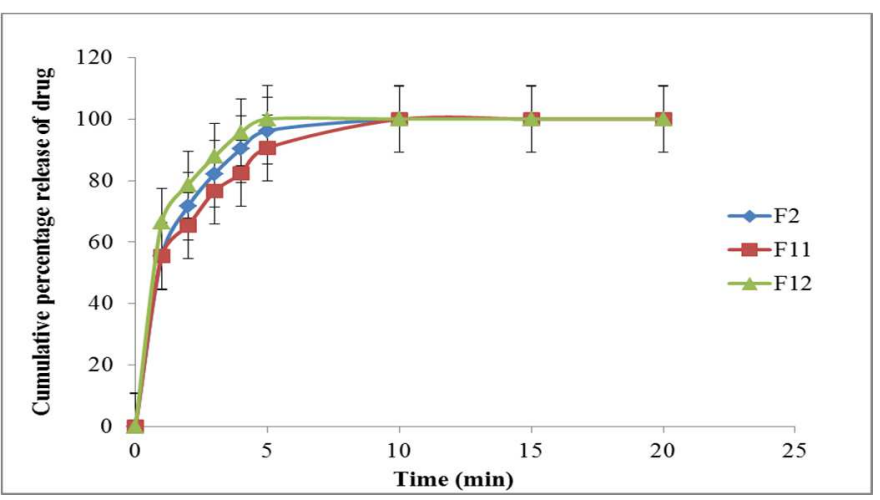

Fig. 10: Cumulative percent of bromocriptine mesylate release from formulas prepared with the different concentration of PEG400 in phosphates buffer ( $\mathrm{pH} \mathrm{6.8)}$ at $37^{\circ} \mathrm{C}$, (All the values were calculated as mean \pm standard deviation; $\mathrm{n}=3$ )

\section{Effect of super-disintegrant (crospovidone) concentration}

Incorporation of super-disintegrant (crospovidone) to the best formula (F12),from the previous study, in different concentrations (1 and 3\% $\mathrm{w} / \mathrm{w}$ ) of the total dry weight of the film represented by (F13 and F14) respectively to study its effect on the physical, mechanical properties and the release profile of bromocriptine mesylate from the film.

The physical properties in the table (3) showed an enhancement in the disintegration time also shown in fig. (11) with the addition of crospovidone to the prepared formula also the disintegration time was more enhanced with increasing the concentration of crospovidone from $1 \%$ to $3 \% \mathrm{w} / \mathrm{w}$ as shown in (F13 and $\mathrm{F} 14$ ) respectively. This disintegration enhancement is caused by the ability of crospovidone to wick saliva quickly into the film that leads to generate the volume expansion and hydrostatic pressures necessary to provide rapid disintegration in the mouth, the major mechanism of disintegration for crospovidone is wicking mechanism in addition to the swelling mechanism [43].

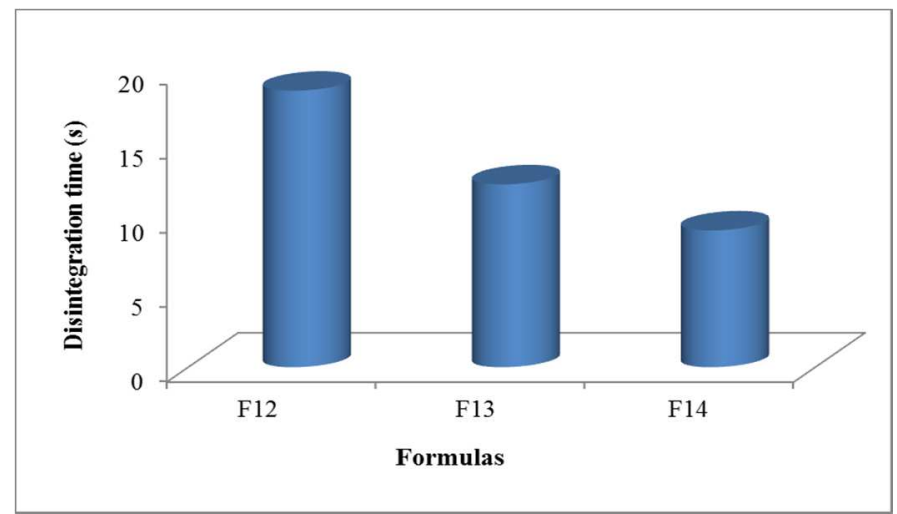

Fig. 11: In vitro disintegration time in seconds of formulas prepared with a different concentration of supper disintegrant (crospovidone), (All the values were calculated as mean \pm standard deviation; $n=3$ ) 
While the mechanical properties for related parameters (percentage of elongation, tensile strength, and Young's modulus) as shown in the table (4) which revealed that there is no significant difference $(\mathrm{P}>0.05)$ with the addition of crospovidone.

On the other hand, adding crospovidone in F13 and F14 (1\% and 3\% respectively) to the prepared bromocriptine mesylate fast dissolving films show a significant difference $(\mathrm{p}<0.05)$ in the dissolution release profile in compares with (F12) prepared without crospovidone as represented by the fig. (12). This result also reported by Deep AK and et al. were they got an increase in disintegration and enhance in dissolution release profile of cinnarizine fast dissolving films by increasing the amount of crospovidone [44]. The release of bromocriptine mesylate mainly depends upon the superdisintegrant concentration. It was found that increase in the content of superdisintegrants, increased the drug release [45]. The enhancement in the release of drug from F13 and F14 can be explained by the porous structure of crospovidone in which the crospovidone particles seem to be granular and highly porous when examined under a scanning electron microscope. This unique, porous particle morphology is acting to wick the liquid, and due to its high crosslink density leading to fast swelling of crospovidone in water without gelling [46].

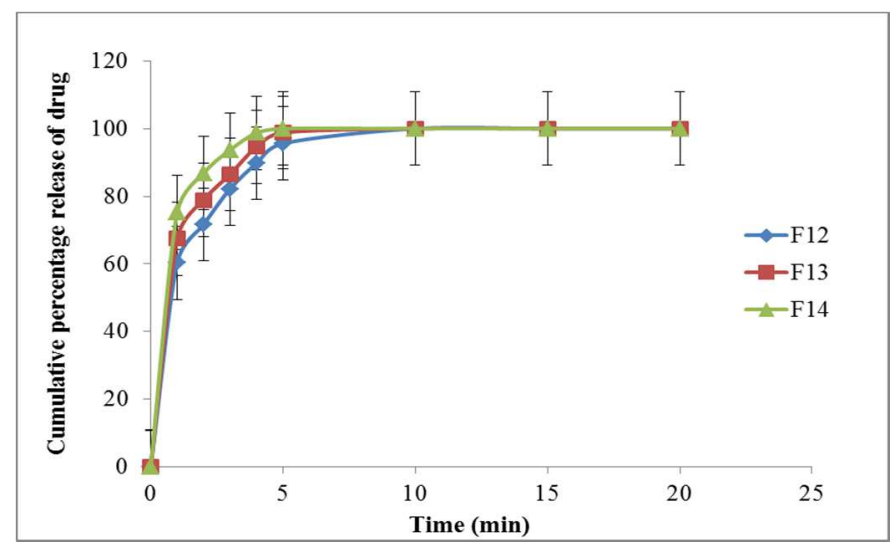

Fig. 12: Cumulative percent of bromocriptine mesylate release from formulas prepared with the different concentration of crospovidone in phosphates buffer ( $\mathrm{pH} \mathrm{6.8)}$ ) at $37^{\circ} \mathrm{C}$, (All the values were calculated as mean \pm Standard Deviation; $\mathrm{n}=3$ )

The time needed for $80 \%$ of medication to be released (T80\%) and percent medication dissolved in $2 \mathrm{~min}$ (\% D2 min) from the formulated fast dissolving oral films (F12, F13and F14) are listed in table (9), which showed that F14 (3\% crospovidone) gave the fastest T80\% $(1.35 \pm 0.3)$ and the highest $\% \mathrm{D} 2 \mathrm{~min}$ $(86.8 \pm 0.1)$.

Table 9: In vitro dissolution parameters from the prepared oral films (F12, F13, and F14)

\begin{tabular}{lll}
\hline Formula code & T80\% (min) mean $\mathbf{S D}$ & D2 min (\%) mean \pm SD \\
\hline F12 & $2.06 \pm 0.25$ & $77.4 \pm 0.65$ \\
F13 & $2.0 \pm 0.1$ & $78.9 \pm 0.2$ \\
F14 & $1.35 \pm 0.3$ & $86.8 \pm 0.1$ \\
\hline
\end{tabular}

SD-Standard deviation; $\mathrm{n}=3$; T $80 \%$-time required for $80 \%$ of drug to be released; $\%$ D2 min-cumulative percentage release of drug at 2 min, according to the results above, F14 was selected as an optimized formula for the formulation of bromocriptine mesylate fast dissolving oral film.

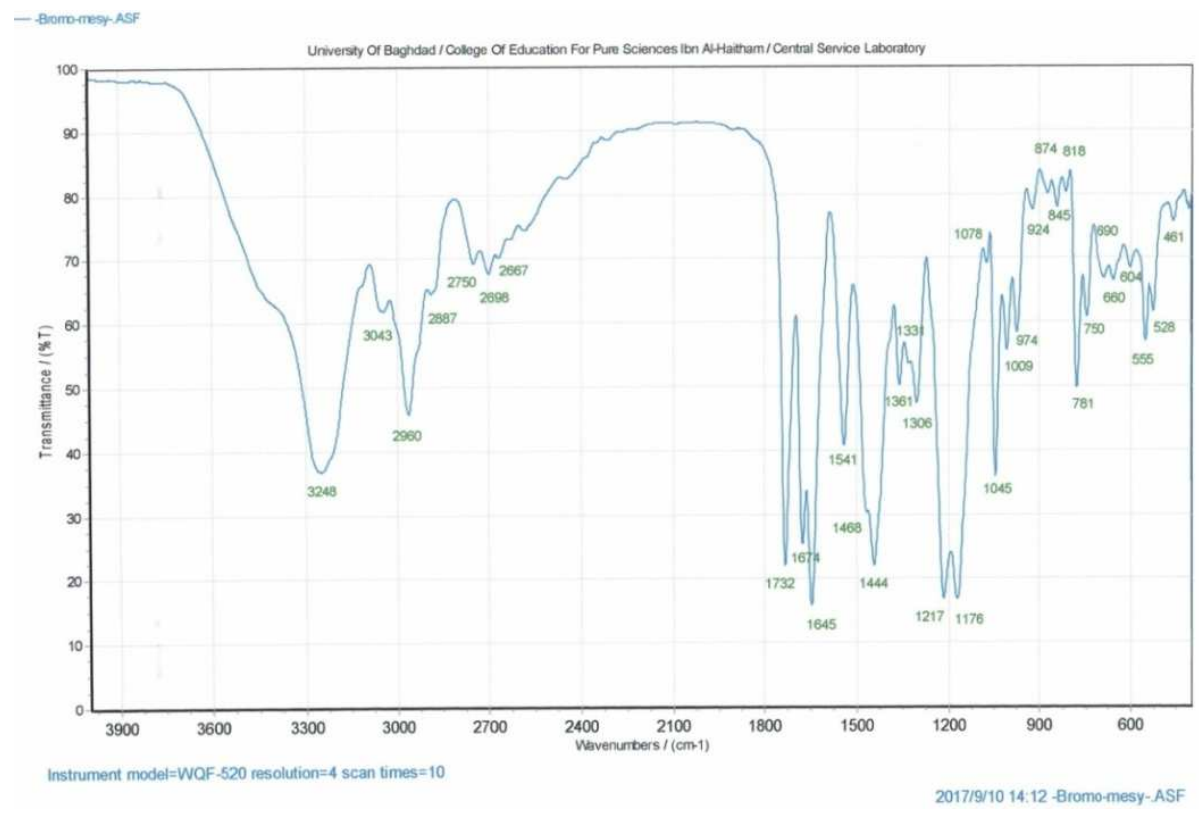

Fig. 13: FTIR spectrum of bromocriptine mesylate 


\section{Drug-polymer compatibility study}

\section{Fourier transform infrared spectroscopy (FTIR)}

The principal peaks of the FT-IR spectrum of bromocriptine mesylate are shown in fig. (13), which is at the wave numbers(in cm1):1047 for alcohol C-H stretching (1260-1000), 1211 for alkyl halide $\mathrm{C}$ - $\mathrm{Br}$ wagging band (1300-1150), 1361 for the $\mathrm{S}=0$ in sulphonate salt (1372-1335), 1444 for aromatic ring (1500-1400),
1544 for amide $\mathrm{N}-\mathrm{H}$ (1650-1515), two bands 1726 and 1672 for $\mathrm{C}=0$ stretching in the ketone group (1870-1540), and 3261 for amide $\mathrm{N}$ H stretching (3350-3180) [47].

Similar peaks were obtained from the bromocriptine in the physical mixture of the selected formula 14 and in the selected formula ( 14 ) as a film as shown in fig. 13, 14 and fig. 15 respectively, this indicates the lack the possibility of interaction between drug and excipients used in the preparation.

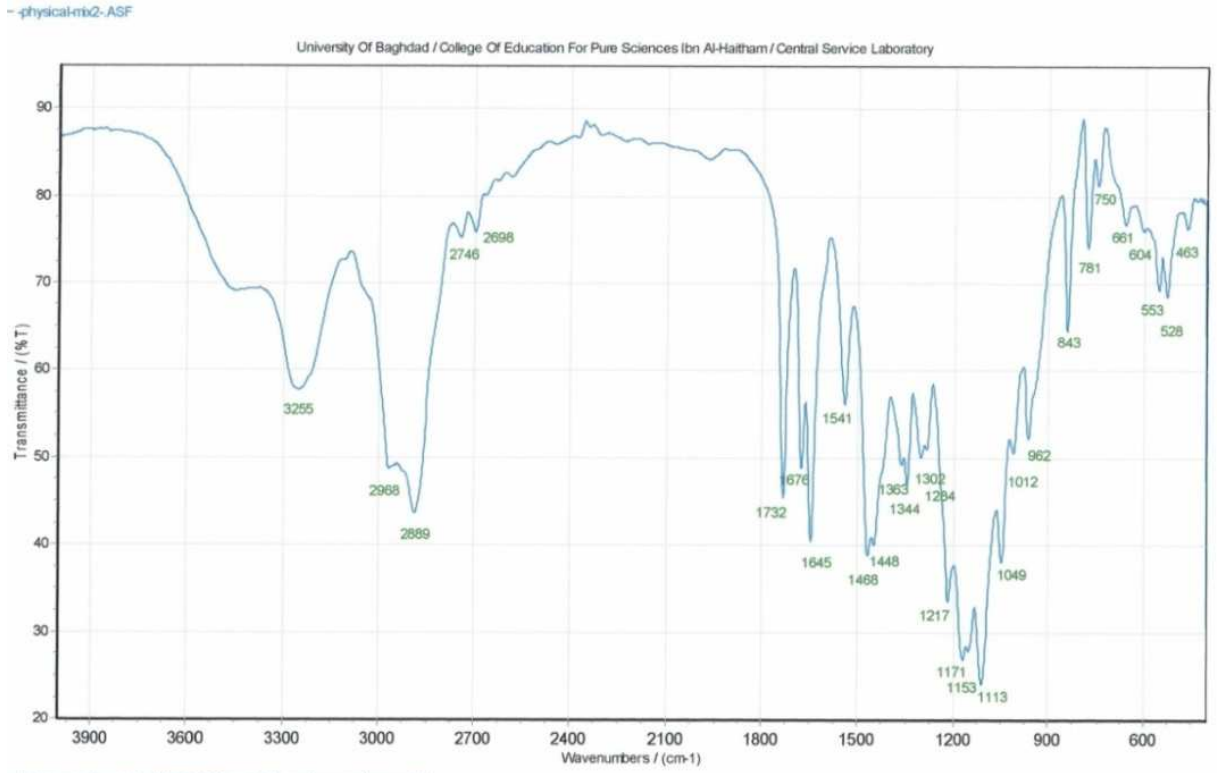

Instrument model=WQF -520 resolution $=4$ scan times $=10$

2017/9/10 13:33-physical-mix2-ASF

Fig. 14: FTIR spectrum of a physical mixture of the selected formula (F14)

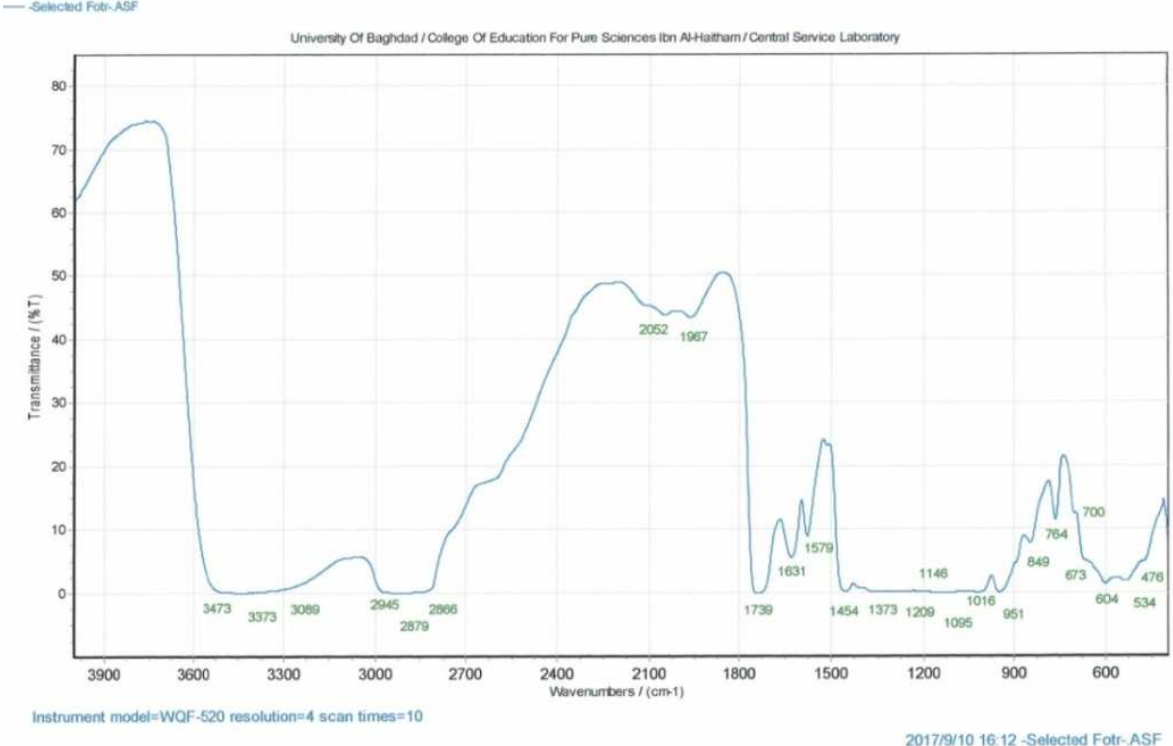

Fig. 15: FTIR spectrum film of the selected formula (F14)

\section{X-Ray diffraction}

The x-ray diffractogram of bromocriptine mesylate confirms its crystalline nature, as evidenced by the number of sharp and intense peaks as shown in fig. (16). However, the diffraction pattern of selected formula F14 represents disappearance of crystalline peaks of the drug, and these findings suggest the improvement of drug solubility by the formation of an amorphous form of the drug. Similar results were observed by Reddy PB et al. [48]. 
A.

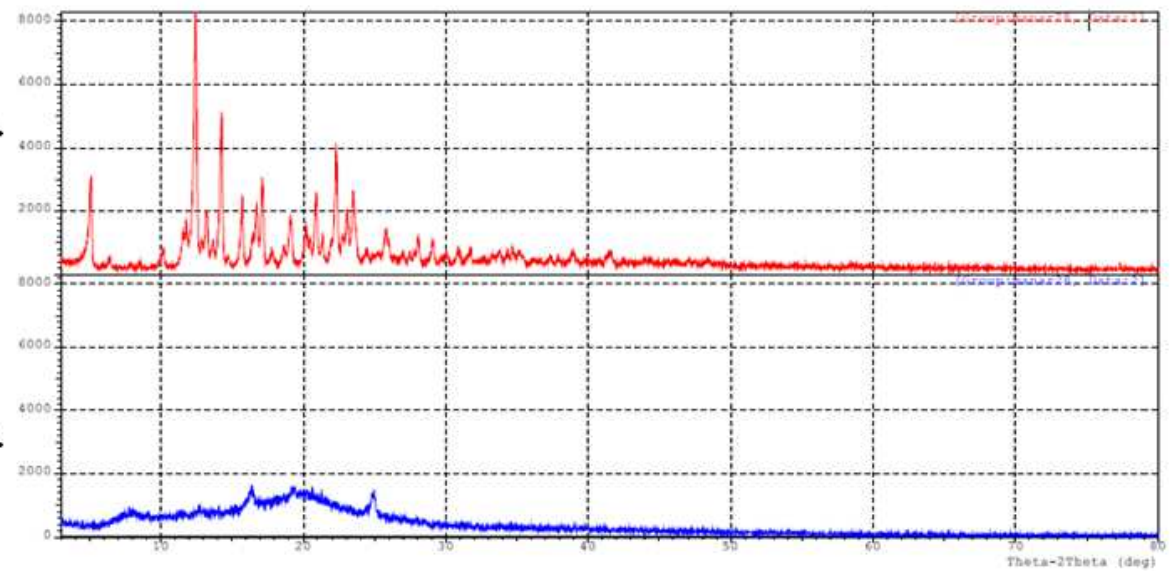

Fig. 16: A. X-Ray diffraction of pure bromocriptine mesylate, B. X-Ray diffraction of the selected formula F14

\section{CONCLUSION}

By the results obtained; hydroxypropyl methylcellulose showed the fastest in vitro disintegration time. In addition, acceptable mechanical properties and dissolution behaviour were achieved. Also, PEG400 was the best plasticizer as it showed an improvement in mechanical and physical characteristics of the bromocriptine mesylate oral film. Formula (F14) which composed from 50\% w/w HPMC E5 as a film forming polymer, 25\% PEG400 as a plasticizer, 5\% poloxamer 407 as a surfactant and $3 \%$ crospovidone as superdisintegrant regarded as an optimized formula with a low disintegration time (9.2 \pm 0.1 seconds), $80 \%$ of drug released within (1.35 minute).

Bromocriptine mesylate administered in the form of fast dissolving films will be a potential novel drug dosage form for geriatric and also for the general population with DM type II by providing faster release and better patient compliance.

\section{ACKNOWLEDGEMENT}

We are very thankful to the ministry of science and technology, research and material department, Iraq; for providing the necessary facilities that help to complete our work.

\section{AUTHORS CONTRIBUTIONS}

All the authors have contributed equally.

\section{CONFLICTS OF INTERESTS}

\section{Declared none}

\section{REFERENCES}

1. Bala R, Pawar P, Khanna S, Arora S. Orally dissolving strips: A new approach to oral drug delivery system. Int J Pharm Investig 2013:3:67-76.

2. Joshua JM, Hari R, Jyothish FK, Surendran SA. Fast dissolving oral thin films: an effective dosage form for quick release. Int J Pharm Sci Rev Res 2016;38:282-9.

3. Patil P, Shrivastava SK. Fast dissolving oral films: an innovative drug delivery system. Int J Sci Res 2014;3:2088-93.

4. Singh G, Saini S, Gill NS. Oral fast dissolving films: an innovative drug delivery system. Int J Univ Pharm Biosci 2014;3:163-77.

5. Krishna KR. Formulation and evaluation of oral fast dissolving film of atazanavir. Indo Am J Pharm Sci 2014;1:182-90.

6. Mahde BW, Ghareeb MM, Abdulrasool AA. Formulation and evaluation of gastroretentive floating tablet of bromocriptine mesilate. Int J Pharm Pharm Sci 2013;5:361-5.

7. Bhattacharjee A. Formulation and evaluation of immediate release tablets of bromocriptine mesylate by direct compression method. Indo Am J Pharm Res 2013;3:2841-5.

8. Shivaprasad C, Kalra S. Bromocriptine in type 2 diabetes mellitus. Indian J Endo Meta 2011;15 Suppl 1:S17-S24.
9. Noor AH, Khalil YI. Formulation and evaluation of felodipine orodispersible films. Pharm Glob 2015;6:1-16.

10. Bhikshapathi DVRN, Madhuri VD, Rajesham VV, Suthakaran R. Preparation and evaluation of fast dissolving oral film containing naratriptan HCl. Am J Pharm Tech Res 2014;4:799-812.

11. Sri KV, Rohini P, Reddy GK. Montelukast sodium oral thin films: formulation and in vitro evaluation. Asian J Pharm Clin Res 2012;5:266-70.

12. Raju S, Reddy PS, Kumar VA, Deepthi A, Reddy KS, Reddy PM, et al. Flash release oral films of metoclopramide hydrochloride for pediatric use: Formulation and in vitro evaluation. J Chem Pharm Res 2011;3:636-46.

13. United States Pharmacopoeia. The USP Convention; 2011. p. 34.

14. Sultana F, Arafat M, Pathan SI. Preparation and evaluation of fast dissolving oral thin film of caffeine. Int J Pharm Biol Sci 2013;3:153-61.

15. Pathan A, Gupta MK, Jain NK, Dubey A, Agrawal A. Formulation and evaluation of fast dissolving oral film of promethazine hydrochloride using a different surfactant. J Inno Pharm Bio Sci 2016;3:74-84.

16. Maheswari KM, Devineni PK, Deekonda S, Shaik S, Uppala NP, Nalluri BN, et al. Development and evaluation of mouth dissolving films of amlodipine besylate for enhanced therapeutic efficacy. J Pharm 2014;3:1-10.

17. Nalluri BN, Sravani B, Anusha VS, Sribramhini R, Maheswari KM. Development and evaluation of mouth dissolving films of sumatriptan succinate for better therapeutic efficacy. J Appl Pharm Sci 2013;3:161-6.

18. Vijayakumar S, Gavaskar B. Overview on fast dissolving films. Int J Pharm Pharm Sci 2010;2:293-317.

19. Rani JL, Abbulu K. Formulation, and evaluation of fast dissolving delivery system of saxagliptin. Int J Chem Pharm Sci 2014;2:862-9.

20. Remidi T, Prasanna K, Mohanty D, Spandana M, Ratnapuram RS. Formulation and in vitro evaluation of oral thin film of mirtazapine. Int J Invent Pharm Sci 2014;2:844-9.

21. Preis M, Pein M, Breitkreutz J. Development of a taste-masked orodispersible film containing dimenhydrinate. Pharmaceutics 2012;4:551-62.

22. Geedi V, Roy SD, Reddy PV. Formulation and evaluation of fast dissolving oral films of zolmitriptan by natural polymers. Int J Adv Pharm 2014;4:57-63.

23. Pragati B, Divya J, Archana D. Fast dissolving films of chlorpheniramine maleate. Am J Pharm Tech Res 2014:4:207-14.

24. Khan S, Kataria P, Nakhat P, Yeole P. Taste masking of ondansetron hydrochloride by polymer carrier system and formulation of rapid-disintegrating tablets. AAPS PharmSciTech 2007;8:127-33.

25. Kumar SK, Nagabhushanam MV, Rao KRSS, Bhikshapathi DVRN. Formulation development and in vivo evaluation of zolmitriptan oral dissolving films. Int J Pharm Bio Sci 2013;4:638-54. 
26. Sagban $\mathrm{TH}$ Ismail YK. Formulation and evaluation of orodispersible film of sildenafil citrate. Int J Pharm Pharm Sci 2014;6:81-6.

27. Tomar A, Sharma K. Formulation and evaluation of fast dissolving film of dicyclomine as a potential route of buccal delivery. Int J Drug Dev Res 2012;4:408-17.

28. Chinnala KM, Panigrahy RN, Bantu R, Sravanthi B. Formulation and evaluation of mouth dissolving films containing tizanidine hydrochloride. Int J Pharm Res Health Sci 2015;3:621-62.

29. Chauhan SS, Lin S, Madan PL. Preparation and evaluation of nicotine hydrogen tartrate fast dissolving films for smoking cessation. Asian J Pharm Sci 2012;7:181-92.

30. Pradhan R, Budhathoki U, Thapa P. Formulation of one-day release tablet of indomethacin based on HPMC-manitol. J Sci Eng Technol Kathmandu University 2008;1:55-67.

31. Manmat GS, Milind LS, Santosh PA, Disouza JI. Fast dissolving HPMC E5 based oral film for rapid absorption of metoprolol tartrate. Eur J Pharm Med Res 2014;1:75-91.

32. Doddayya H, Patil SS, Sree GR, Waseem H, Udupi RH. Design and in vitro evaluation of fast dissolving films containing HP $\beta$ CD inclusion complexes of lamotrigine. J Drug Delivery Ther 2014;4:99-106.

33. Sapkal NP, Kilor VA, Daud AS, Bonde MN. Development of fast dissolving oral thin films of ambroxol hydrochloride: effect of formulation variables. J Adv Pharm Res 2011;2:102-9.

34. Kaza R, Elevate PR, Ravouru N. Design, and characterization of fast dissolving films of valsartan. Turkish J Pharm Sci 2014;11:175-84.

35. Trivedi J, Patel J, Patel U. Formulation development and evaluation of fast dissolving film of cinnarizine. Int J Pharm Biol 2014;3:639-52.

36. Salman ZD, Marie NK, Alabbassi MG, Ghareeb MM. In vitro/in vivo evaluation and bioavailability study of amitriptyline hydrochloride from the optimized oral fast dissolving films. UK J Pharm Biol 2014;2:32-42.
37. Ali MS, Vijendar C, Kumar S, Krishnaveni J. Formulation and evaluation of fast dissolving oral films of diazepam. J Pharmacovigilance 2016;4:210-5.

38. Choudhary DR, Patel VA, Chhalotiya UK, Patel HV, Kundawala AJ. Formulation and evaluation of fast dissolving film of levocetirizine dihydrochloride using different grades of methocel. J Pharm Res 2011;4:2919-24.

39. Abd-Alhammid SN, Saleeh HH. Formulation and evaluation of flurbiprofen oral film. Iraqi J Pharm Sci 2014;23:53-9.

40. Jadhav YG, Galgatte UC, Chaudhari PD. Challenges in formulation development of fast dissolving oral film. Indo Am J Pharm Res 2013;3:6391-407.

41. Chauhan SS, Lin S, Madan PL. Preparation and evaluation of nicotine hydrogen tartrate fast dissolving films for smoking cessation. Asian J Pharm Sci 2012;7:181-92.

42. Miller Dave A., McGinty James W, Aqueous polymeric film coating, in Augsburger Larry L, Hoag Stephen W. eds. Pharmaceutical dosage forms: Tablets. $3^{\text {rd }}$ ed. New York: Information Health Care; 2008.

43. Gupta AM, Gupta V, Bansal P, Singh R, Singh AK. Recent trends of fast dissolving tablet-an overview of formulation technology. Int J Pharm Biol Arch 2010;1:1-10.

44. Heer DA, Aggarwal G, Hari Kumar SL. Development of fast dissolving oral films and tablet of cinnarizine: effect of superdisintegrants. Int J Pharm Pharm Sci 2014;6:186-91.

45. Archana G, Raju PN, Reddy GN. Formulation and in vitro evaluation of atazanavir oral disintegrating tablets. Asian J Pharm Clin Res 2014;7:184-8.

46. Mohanachandran PS, Sindhumol PG, Kiran TS. Superdisintegrant: an overview. Int J Pharm Sci Rev Res 2011;6:22.

47. Robert MS, Frances XW, David JK. Spectrometric identification of organic compounds. $7^{\text {th }}$ ed. New York: John Wiley; 2005.

48. Reddy PB, Varma MM, Betha S, Basava DR, Mecha R, Ratna JV. Formulation, development and characterization of chlorpheniramine maleate mouth dissolving films. Pelagia Res Lib 2013:4:1-9. 